\title{
Regulation of chlorogenic acid, flavonoid, and iridoid biosynthesis by histone H3K4 and H3K9 methylation in Lonicera japonica
}

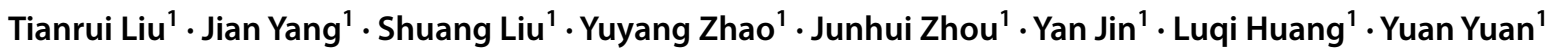

Received: 30 July 2020 / Accepted: 6 November 2020 / Published online: 15 November 2020

(c) Springer Nature B.V. 2020

\begin{abstract}
Lonicera japonica is used in Chinese herbal medicines with a wide spectrum of pharmacological properties associated with chlorogenic acid, flavonoid and iridoid. The biosynthesis of these compounds could be affected by genetic inheritance and epigenetic modification. However, the mechanisms that regulate the expression of genes involved in the biosynthesis of these compounds are rarely known. The results of qRT-PCR showed that the biosynthesis gene expression of these compounds was related to histone $\mathrm{H} 3 \mathrm{~K} 4$ and $\mathrm{H} 3 \mathrm{~K} 9$ methylation levels. These active compounds content of $L$. japonica were measured by UPLC-MS/MS. H3K4me3 showed a positive correlation with chlorogenic acid and loganic acid content, and H3K9me positively correlated with luteolin content. The correlation between histone methylation levels and the levels of luteolin and loganic acid in L. japonica from different producing areas validate the regulatory role of histone methylation in biosynthesis of bioactive compounds. Our study demonstrated a potential regulatory network of H3K9/H3K4 methylation to gene expression and content of secondary metabolites, and provided a basis for understanding the mechanism underlying the variation of major bioactive compounds in L. japonica.
\end{abstract}

Keyword Bioactive compounds $\cdot$ Different producing areas $\cdot$ Histone methylation $\cdot$ Lonicera japonica

\begin{tabular}{ll} 
Abbreviations & \\
PAL & Phenylalanine ammonia-lyase \\
C4H & Cinnamate 4-hydroxylase \\
4CL & 4-Coumarate CoA ligase \\
HQT & $\begin{array}{l}\text { Hydroxycinnamoyl-CoA quinate } \\
\text { transferase }\end{array}$ \\
CHI & Chalcone isomerase \\
& \\
\hline
\end{tabular}

Tianrui Liu, Jian Yang, and Shuang Liu contributed equally to this work.

Electronic supplementary material The online version of this article (https://doi.org/10.1007/s11033-020-05990-7) contains supplementary material, which is available to authorized users.

Yuan Yuan

y_yuan0732@163.com

Tianrui Liu

raymond50@live.cn

Jian Yang

yangchem2012@163.com

Shuang Liu

scarlett0706@163.com

Yuyang Zhao

zhaoyuyang0618@163.com

$\begin{array}{ll}\text { CHS } & \text { Chalcone synthase } \\ \text { IPP } & \text { Isopentenyl pyrophosphate } \\ \text { DMAPP } & \begin{array}{l}\text { Dimethylallyl diphosphate triammonium } \\ \text { salt }\end{array} \\ \text { GPP } & \text { Geranyl pyrophosphate } \\ \text { GPPS } & \text { GPP synthase } \\ \text { GES } & \text { Geraniol synthase } \\ \text { G10H } & \text { Geraniol-10-hydroxylase } \\ \text { 10HGO } & \text { 10-Hydroxygeraniol } \\ \text { IS } & \text { Iridoid synthase } \\ \text { 5-azaC } & \text { 5-Azacytidine } \\ \text { ORFs } & \text { Open reading frames } \\ \text { HMT } & \text { Histone methyltransferase }\end{array}$

Junhui Zhou

jh-zhou@outlook.com

Yan Jin

jy20047@163.com

Luqi Huang

huangluqi01@126.com

State Key Laboratory of Dao-Di Herbs, National Resource Center for Chinese Materia Medica, China Academy of Chinese Medical Sciences, Beijing 100700, People's Republic of China 


\begin{tabular}{|c|c|}
\hline HDT & Histone demethylase \\
\hline $\mathrm{H} 3 \mathrm{~K} 4 m e 1 / 2 / 3$ & $\begin{array}{l}\text { Monomethylation/dimethylation/trimeth- } \\
\text { ylation of histone } \mathrm{H} 3 \text { at lysine } 4\end{array}$ \\
\hline H3K $9 m e 1 / 2 / 3$ & $\begin{array}{l}\text { Monomethylation/dimethylation/trimeth- } \\
\text { ylation of histone } \mathrm{H} 3 \text { at lysine } 9\end{array}$ \\
\hline 3LS & (3S)-linalool/(E)-nerolidol synthase \\
\hline IO & Iridoid oxidase \\
\hline $7 \mathrm{H} 7 \mathrm{D}$ & 7-Deoxyloganic acid 7-hydroxylase \\
\hline $8 \mathrm{HD}$ & 8-Hydroxygeraniol dehydrogenase \\
\hline LAM & (E)-beta-ocimene/myrcene synthase \\
\hline MOS & (E)-beta-ocimene/myrcene synthase \\
\hline $\mathrm{C}$ & Ecologanin synthase \\
\hline
\end{tabular}

\section{Introduction}

Lonicera japonica is an important medicinal herb and its buds are used in the preparation of herbal tea in East-Asia including China, Japan, and Korea [1]. L. japonica buds are widely used to treat pancreatic cancer [2], H1N1 influenza infection [3], severe acute respiratory syndrome, and handfoot-and-mouth disease [4].

The major bioactive components of $L$. japonica are chlorogenic acids, flavonoids and iridoids [5-7]. Chlorogenic acids possess anti-oxidative, anti-hypoxic, antibacterial, antiviral, and anti-inflammatory properties [8-15]. Luteoloside inhibits the risk of cardiovascular disease, severe acute respiratory syndrome [16], and hepatitis, and ameliorates intervertebral disk degeneration [17]. Other pharmaceutically active metabolites include iridoids and secoiridoids, and over 30 iridoids have been identified in L. japonica in the past decades $[18,19]$. Loganin possesses anti-inflammatory and anti-shock effects [20-23].

Phenylalanine ammonia-lyase (PAL), cinnamate 4-hydroxylase $(\mathrm{C} 4 \mathrm{H})$, and 4-coumarate CoA ligase (4CL) are essential enzymes required for the initial steps of chlorogenic acid and luteoloside biosynthesis. HydroxycinnamoylCoA quinate transferase (HQT) is a key enzyme acting downstream of the chlorogenic acid metabolic pathway [24]. Chalcone isomerase (CHI) is required for the conversion of naringenin chalcone to naringenin and is considered an essential enzyme for the biosynthesis of flavonoids [25] (Fig. S1A). Isopentenyl pyrophosphate (IPP) and dimethylallyl diphosphate triammonium salt (DMAPP) were produced by the mevalonate (MVA) and methylerythritol 4-phosphate (MEP) pathways. IPP and DMAPP condense to form geranyl pyrophosphate (GPP) in a reaction catalyzed by GPP synthase (GPPS). Geraniol synthase (GES) catalyzes the formation of geraniol from GPP. Geraniol is converted to 10-hydroxygeraniol by the geraniol-10-hydroxylase $(\mathrm{G} 10 \mathrm{H})$, and 10-hydroxygeraniol is converted to 10-oxogeranial by 8 -hydroxygeraniol dehydrogenase (10HGO). Finally, 10-oxogeranial is converted to epi-iridodial by iridoid synthase (IS) [26] (Fig. S1B).

Lonicera japonica plantation accounts for more than 360,000 hectares of land in China, and the production of $L$. japonica flower buds is about 26,000 tons per year. In 2010, the domestic demand for L. japonica flower buds exceeded 80,000 tons, and the demand has increased annually since then. Analysis of gene transcript levels have shown that a variation in active compound content changes the pharmacological activities and medicinal qualities owing to artificial selection in germplasm, tissue, different growth stages, and pruning [27]. The synthesis and accumulation of chlorogenic acids and luteoloside at different growth stages and different tissues [28-30] in L. japonica also correlated with variations in the activities of enzymes involved in the metabolism of phenylalanine, which included PAL, C4H, and 4CL. The synthesis and accumulation of chlorogenic acid was directly affected by variations in HQT activity, and the synthesis of luteoloside was directly affected by variations in CHI activity. Pruning decreased HQT and CHI gene expression, which led to a decrease in chlorogenic acid and luteoloside content in the flower bud of L. japonica.

However, plant introduction is the most important factor affecting the variation of active compounds during cultivation. The north of China is a traditional L. japonica producing area, and seedlings from this region have been introduced to many places with different ecological characteristics. There is a crucial need to improve the chemical quality of L. japonica for population growth, and the change in active compounds after plant introduction is largely regulated by epigenetic modifications. There is growing evidence indicating that plants employ sophisticated epigenetic mechanisms to fine-tune their responses to environmental stress following plant introduction. Epigenetic processes and elements, including DNA methylation, histone modification, chromatin remodeling, and noncoding RNAs, are involved in plant responses to abiotic and biotic stresses [31]. A previous report has revealed the presence of several miRNAs involved in the regulation of fatty acid and flavonoid biosynthesis in different varieties of L. japonica from different regions [32]. However, epigenetic variations in the bud of L. japonica after plant introduction and their correlation with accumulation of chlorogenic acids, luteoloside, and iridoids remain largely unknown.

Histone modification, including histone methylation and demethylation, is one of the most common types of epigenetic regulation and has been widely studied. Histone modification regulates development and responses to biotic and abiotic stresses in plants [33]. The majority of histone methylation takes place on the lysine residue of histone $\mathrm{H} 3$ in which $\mathrm{H} 3 \mathrm{~K} 4$ and $\mathrm{H} 3 \mathrm{~K} 9$ are highly conserved epigenetic markers for gene activation [34, 35]. Histone methylation is dynamically regulated by histone methyltransferases (HMTs) 
and histone demethylases (HDMs) [31, 36]. In this study, we reported for the first time the potential mechanism of bioactive compound biosynthesis regulated by $\mathrm{H} 3 \mathrm{~K} 4$ and H3K9 methylation in L. japonica, and elucidated the correlation among transcriptional levels of $H M T s$ and HDTs, histone methylation levels, and bioactive compounds of $L$. japonica. This work will provide a basis for understanding the epigenetic mechanism of bioactive compound synthesis and gene expression regulated by $\mathrm{H} 3 \mathrm{~K} 4$ and $\mathrm{H} 3 \mathrm{~K} 9$ methylation in L. japonica.

\section{Material and methods}

\section{Plant materials}

Fresh buds of $L$. japonica were collected from Yunnan, Beijing, Hebei, and Hubei provinces of China, and the seedlings in Yunnan, Hebei, and Hubei were introduced from Beijing. Fresh leaves of $L$. japonica were treated with $80 \mu \mathrm{M} 5$-azacytidine (5-azaC) for $48 \mathrm{~h}$, while untreated leaves served as control. The treated and untreated leaves were from the same trees, and the leaves were stored at $-80{ }^{\circ} \mathrm{C}$ until use. All experiments were performed in triplicate.

\section{Methods}

\section{RNA isolation, cDNA synthesis, and cloning}

Total RNA was extracted using TRIzol reagent (Invitrogen, Carlsbad, CA, USA). An aliquot of $1 \mu \mathrm{g}$ of total RNA was used to synthesize the first strand of cDNA using PrimeScript $1{ }^{\text {st }}$ Strand cDNA Synthesis Kit (Takara Bio, Dalian, China), according to the manufacturer's protocol. Each cDNA was cloned using PrimeSTAR DNA polymerase (Takara Bio). Full-length cDNAs of HMTs and HDTs were cloned using PrimeSTAR ${ }^{\circledR}$ HS DNA polymerase (TaKaRa Biotechnology Co., Dalian, China) and ORF-PCR primers (Table 1).

\section{Gene cloning and bioinformatics analysis}

The cDNA sequences of HMTs and HDTs were obtained from the $L$. japonica transcriptome database [28]. The open reading frames (ORFs) and deduced amino acid sequences of HMTs and HDTs were analyzed using ORF Finder (https ://www.ncbi.nlm.nih.gov/gorf/gorf.html). The structural and functional domains were predicted by NCBI's conserved domain database (https://www.ncbi.nlm.nih.gov/Structure/ cdd/wrpsb.cgi). The neighbor-joining method was used to construct phylogenetic trees of HMTs and HDTs using MEGA 6.06 software. The phylogenetic tree was constructed based on the amino acid sequences of HMTs and HDTs from L. japonica and other species (Table S1).

\section{Total histone extraction and concentration determination}

Total core histone proteins ( $\mathrm{H} 2 \mathrm{~A}, \mathrm{H} 2 \mathrm{~B}, \mathrm{H} 3$, and $\mathrm{H} 4)$ of L. japonica were extracted using EpiQuik ${ }^{\mathrm{TM}}$ Total Histone Extraction Kit (Epigentek, USA), according to the kit manufacturer's instructions. The total core histones were extracted by treatment with pre-lysis, lysis, and balance buffers. Post-translational modifications were kept intact and did not affect histone modification status or levels. The total histone concentration was determined using Modified Bradford Protein Assay Kit (Sangon Biotech, Shanghai, China), and histone concentration was calculated from the histone concentration curve.

\section{Analysis of $\mathrm{H} 3 \mathrm{~K} 4$ and $\mathrm{H} 3 \mathrm{~K} 9$ methylation levels}

Bioinformatics analysis showed that HMTs and HDTs were involved in $\mathrm{H} 3 \mathrm{~K} 4$ and $\mathrm{H} 3 \mathrm{~K} 9$ methylation. Therefore, methylation levels of histones $\mathrm{H} 3 \mathrm{~K} 4$ and $\mathrm{H} 3 \mathrm{~K} 9$ were measured using the EpiQuik ${ }^{\mathrm{TM}}$ Global Pan-Methyl Histone H3K4 Quantification Kit (Fluorometric, Epigentek, USA) and the EpiQuik $^{\mathrm{TM}}$ Global Pan-Methyl Histone H3K9 Quantification Kit (Fluorometric, Epigentek, USA), respectively, following the kit manufacturer's instructions.

Subsequently, H3K4 and H3K9 methylation curves were established. The standard curves included: (1) protein
Table 1 PCR primers used for cloning full-length cDNAs of HMTs and HDTs

\begin{tabular}{lll}
\hline Primer name & Primer sequence $\mathrm{F}\left(5^{\prime} \rightarrow 3^{\prime}\right)$ & Primer sequence $\mathrm{R}\left(5^{\prime} \rightarrow 3^{\prime}\right)$ \\
\hline HMT1 & ATGATTTACGATTCCCTTAGGGTT & TTAGTTACAAATGGGAAGCTTCCC \\
HMT2 & ATGGGGAGCTCAGCTAACGGCTTC & TCATTCTATGTAGTACTTGCTTTTG \\
HMT3 & ATGGAGGTTCCTCAAGTTCAAAAGCA & TCAATGGAGCTCAGCACCCGAACC \\
HMT4 & ATGGAACAAGGAGTGGGTTCGGACT & CTAGTAAAAACAGCCCCTGCACTTC \\
HDT1 & ATGGAAGTACTAATTGCAAAGCAA & TCATTGCCAGGTAGACGCCAGAGC \\
HDT2 & ATGACTTTCAGCGGCGAAGGAAGGG & TCATTGCCAGGTAGACGCCAGAGC \\
HDT3 & ATGGGAATGGAACGCATGGGAACTTG & TCATTGCCAGGTAGACGCCAGAGC \\
HDT4 & ATGACAGGCGATAACGGAGTTGTTG & TCAGCTTATGCTGGCCCTACTGGATC \\
\hline
\end{tabular}


concentration vs. absorbance value, $Y=0.02 X+0.3124$ $(r=0.9895)$; (2) H3K4 methylation level vs. fluorescence value, $Y=87.532 X+0.1914(r=0.9903)$; and (3) H3K9 methylation level vs. fluorescence value, $Y=93.662 X+0.1691(r=0.9882)$.

Based on the fluorescence value of $530_{\mathrm{EX}} / 590_{\mathrm{EM}} \mathrm{nm}$, $\mathrm{H} 3 \mathrm{~K} 4$ and $\mathrm{H} 3 \mathrm{~K} 9$ methylation levels were calculated from the H3K4 and H3K9 methylation curves. The concrete formula used for calculation of relative methylation level was: Amount of protein $(\mathrm{ng} / \mathrm{mg})=$ RFU $($ sample - blank $) \times 1000$ $/$ protein $(\mu \mathrm{g}) \times$ slope

\section{Gene expression analysis}

Transcriptional levels of HMTs, HDTs, and key genes involved in active compound biosynthesis were analyzed using quantitative real-time polymerase chain reaction (qRT-PCR). The specificity of amplification was assessed using melting curve analysis, and the relative expression of genes was determined using the comparative $\mathrm{Ct}$ method. qRT-PCR analysis was performed using LightCycler ${ }^{\circledR} 480$ and SYBR ${ }^{\circledR}$ Premix Ex Taq ${ }^{\mathrm{TM}}$ (TaKaRa Biotechnology Co., Dalian, China), according to the manufacturer's protocol. The house-keeping gene Lj18S was used as an internal control for each reaction. Primers for HMTs, HDTs, key genes involved in active compound biosynthesis, and housekeeping gene were designed using Primer Premier 5.0 (Table S2). The relative gene expression level compared to that of control was calculated using the $2^{-\Delta \mathrm{Ct}}$ method.

\section{UPLC-MS/MS analysis and quantification}

Chromatographic analysis was performed using Acquity UPLC I-Class system (Waters, Milford, MA, USA). The column used was Acquity UPLC BEH $\mathrm{C}_{18}$ column $(2.1 \mathrm{~mm} \times 100 \mathrm{~mm}, 1.8 \mu \mathrm{m})$, and the column temperature was maintained at $40{ }^{\circ} \mathrm{C}$. The binary gradient consisted of solvent system A (formic acid/water, 0.1:99.9, v/v) and solvent system B (formic acid/acetonitrile, 0.1:99.9, v/v). The chromatographic conditions were as follows: 0 min, $5 \% \mathrm{~B}$; $5.5 \mathrm{~min}, 30 \% \mathrm{~B}$. The injection volume was $1.0 \mu \mathrm{L}$, and the flow rate was $0.50 \mathrm{~mL} \cdot \mathrm{min}^{-1}$.

Tandem mass spectrometry (MS/MS) was performed using QTRAP 6500 system (AB SCIEX, Los Angeles, CA, USA) equipped with an electrostatic ionization (ESI) source (AB SCIEX). MS analysis was carried out in negative ionization mode by monitoring the protonated molecular ions under the following operating conditions: ion source voltage, $-4500 \mathrm{~V}$; and turbo spray temperature (TEM), $550{ }^{\circ} \mathrm{C}$. The MS parameters for chlorogenic acids, flavonoids, and iridoids were manually optimized. Quantification was performed using multiple reaction monitoring (MRM) mode for the above transitions. Data were acquired using Analyst Software 1.6.2 (AB SCIEX, Los Angeles, CA, USA) and analyzed using MultiQuant Software 3.0 (AB SCIEX, Los Angeles, CA, USA).

To investigate the active compounds of $L$. japonica treated with 5-azaC, ultra performance liquid chromatography-tandem mass spectrometry (UPLC-MS/MS) was performed. The optimized mass spectrum conditions of UPLC-MS/ MS for chlorogenic acids, flavonoids, and iridoids are given in Table S3. Linear relation tests revealed that these compounds had a good linear relationship $(r>0.995)$ in their linearity ranges (Table S4).

\section{Results}

\section{Sequence analyses of HMTs and HDTs}

A preliminary BLASTx search was performed using the transcriptome sequencing dataset of $L$. japonica. The sequences of four HMTs and four HDTs of L. japonica were screened out and submitted to GenBank (accession numbers: KX812448-KX812455). Details of the HMTs and HDTs are shown in Table 2.

The HMT1 gene was 1485 bp in length, and it encoded 494 amino acids. The isoelectric point (pI) value and the

Table 2 Sequences of four HMTs and four HDTs of L. japonica

\begin{tabular}{lllllrl}
\hline Name & Accession number & $\begin{array}{l}\text { Sequence } \\
\text { length }(\mathrm{bp})\end{array}$ & $\begin{array}{l}\text { Amino acids } \\
\text { number }(\mathrm{aa})\end{array}$ & pI & MW/KDa & Conserved domains \\
\hline HMT1 & KX812448 & 1485 & 494 & 6.18 & 55.84 & SET \\
HMT2 & KX812449 & 1140 & 379 & 5.31 & 42.75 & AdoMet-MTases \\
HMT3 & KX812450 & 1614 & 537 & 5.43 & 59.89 & AdoMet-MTases, PRMT5 \\
HMT4 & KX812451 & 2187 & 728 & 8.55 & 80.05 & SAD-SRA, Pre-SET, SET \\
HDT1 & KX812452 & 3567 & 1188 & 6.82 & 136.34 & JmjC \\
HDT2 & KX812453 & 3018 & 1005 & 5.57 & 113.98 & JmjC \\
HDT3 & KX812454 & 2226 & 741 & 7.88 & 84.93 & JmjC, JmjN \\
HDT4 & KX812455 & 1578 & 525 & 5.35 & 57.78 & FAD/NAD, Amino oxidase, SWIRM \\
\hline
\end{tabular}


molecular weight (MW) of the HMT1 protein were calculated using the Compute $\mathrm{pI} / \mathrm{Mw}$ tool of the ExPASy online server and found to be 6.18 and $55.84 \mathrm{kDa}$, respectively, and it contained one functional conserved domain i.e., the SET domain. The HMT4 gene was $2187 \mathrm{bp}$ in length, and it encoded 728 amino acids. The pI value and MW of the HMT4 protein were 8.55 and $80.05 \mathrm{kDa}$, respectively, and it contained three conserved domains, including SAD-SRA, Pre-SET, and SET.

The HDT2 gene was 3018 bp in length, and it encoded 1005 amino acids. The pI value and MW of the HDT2 protein were 5.57 and $113.98 \mathrm{kDa}$, respectively, and it contained the JmjC conserved domain.

In order to better understand the functional details of HMTs and HDTs, phylogenetic trees were constructed with the amino acid sequences of histone methyltransferases and demethylases of other species using the neighbor-joining method. The bootstrap condition was 1000 times. Description of different types of histone methyltransferases and demethylases used in construction of phylogenetic trees are listed in Table S1.

Based on sequence similarity, the identified HMTs were clustered into two subgroups. It was observed that HMT1 and HMT4 of $L$. japonica and histone lysine methyltransferases were clustered in one clade (Fig. 1a). Therefore, HMT1 and HMT4 of L. japonica containing the SET domain were considered to be histone lysine transferases, combined with phylogenetic analysis, suggested that HMT1 and HMT4 belong to histone $\mathrm{H} 3 \mathrm{~K} 9$ methyltransferases group. Moreover, it was observed that HMT4 of L. japonica was located close to histone methyltransferase H3 lysine-9 specific SUVH1 of A. thaliana, and SUVH1 was found to maintain H3K4 methylation levels. Similarly, HDT2 were closely related to lysine-specific demethylase JMJ25 (Fig. 1b), which removes H3K4 methyl markings in gene bodies.

\section{Dynamic changes in the levels of HMTs/ HDTs and H3K4/H3K9 methylation levels in 5-azaC-treated samples}

Expression levels of HMTs and HDTs were analyzed using qRT-PCR, and it was observed that 5-azaC treatment significantly decreased the expression levels of HMT1 and HMT4 $(p<0.05)$ and increased the expression levels of HMT2, HMT3, and HDT2 $(p<0.05)$ (Fig. 2).

Our results (Fig. 3) suggest that histone H3K9 methylation level increased after 5-azaC treatment because HMT1, HMT4, and HDT2 were all related to histone H3K9. Analysis of H3K4 and H3K9 methylation levels further showed that 5-azaC treatment significantly decreased $\mathrm{H} 3 \mathrm{~K} 4 \mathrm{me} 3$ methylation level and significantly increased $\mathrm{H} 3 \mathrm{~K} 9 \mathrm{me} 1$, H3K9me2, and H3K9me3 methylation levels.

\section{Chlorogenic acid, flavonoid, and iridoid content in 5-azaC-treated samples}

In L. japonica treated with $80 \mu \mathrm{M} 5$-azaC for $48 \mathrm{~h}$, it was observed that the levels of chlorogenic acids (chlorogenic acid, neochlorogenic acid, cryptochlorogenic acid, isochlorogenic acid $\mathrm{A}$, and isochlorogenic acid $\mathrm{C}$ ) and iridoids (loganic acid, loganin, secoxyloganin, and 7-epi-loganin) were significantly decreased $(p<0.05)$, whereas the level
Fig. 1 Phylogenetic tree of HMTs and HDTs. a Phylogenetic tree of HMTs; and $\mathbf{b}$ phylogenetic tree of HDTs. The bootstrap was 1000
A

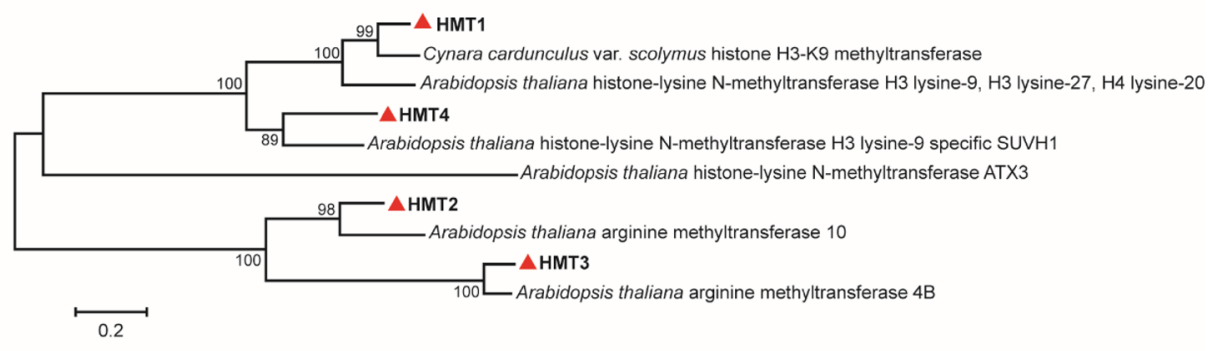

B

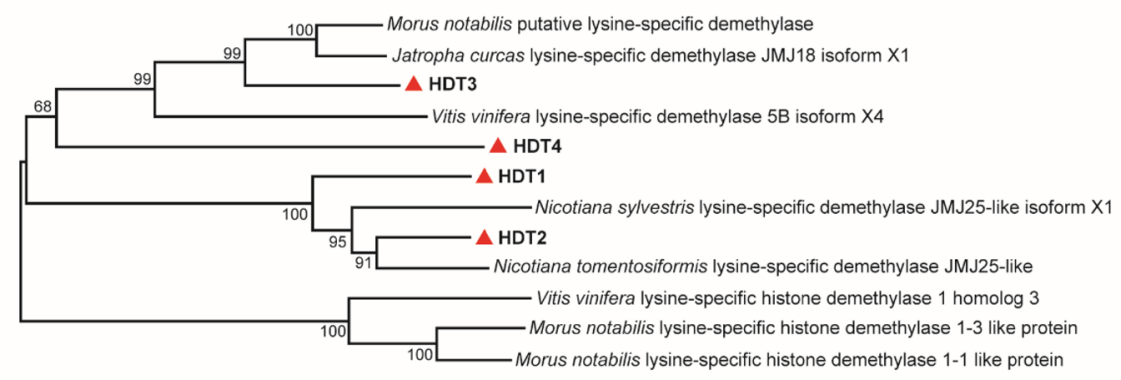


of flavonoids (luteolin and luteoloside) was significantly increased as compared to the control group (Table 3).

The results of qRT-PCR showed that the gene expression levels of HQT and 8HD1 decreased, while the expression levels of PAL, CHS, CHI, and FNSII increased significantly after 5-azaC treatment as compared to control. As the number of cycles in the logarithmic phase was greater than 35, it was considered that (3S)-linalool/(E)nerolidol synthase (3LS), (E)-beta-ocimene/myrcene synthase (MOS), iridoid oxidase (IO), 7-deoxyloganic acid 7-hydroxylase (7D7H), ecologanin synthase (SS), and (E)-beta-ocimene/myrcene synthase (LAM) genes were not expressed or expressed at very low levels (Fig. 4). These results were in accordance with the content of bioactive compounds in L. japonica.

Loganic acid and chlorogenic acid content showed significant positive correlation with $\mathrm{H} 3 \mathrm{~K} 4 \mathrm{me} 3$ methylation level $(p<0.05)$; whereas, H3K9 methylation level showed significant positive correlation with luteolin content $(p<0.05)$ (Table S5).
Fig. 2 Relative gene expression levels of HMTs and HDTs in L. japonica. a Gene expression level of $H M T s$; and $\mathbf{b}$ gene expression level of $H D T s$. Control group, untreated leaves; 5 -azaC group, leaves treated with 5-azaC; *compared with the control group, $p<0.05$
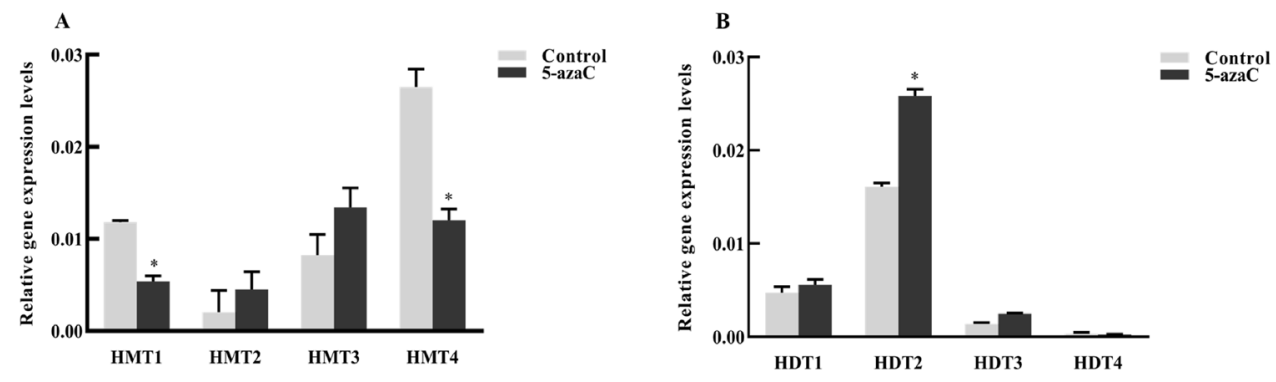

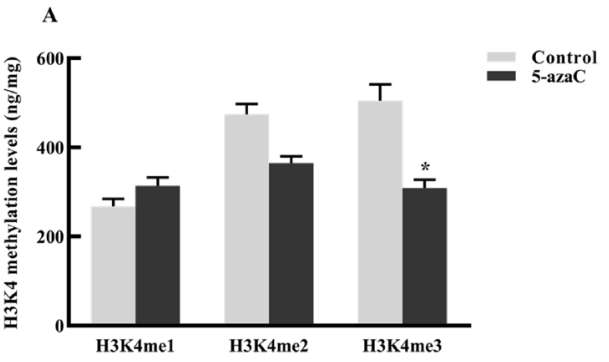

Fig. 3 Histone methylation levels in untreated and 5-azaC-treated leaves of $L$. japonica. a H3K4 methylation levels; and b $\mathrm{H} 3 \mathrm{~K} 9$ methylation levels. Control group, untreated leaves; 5-azaC group, leaves

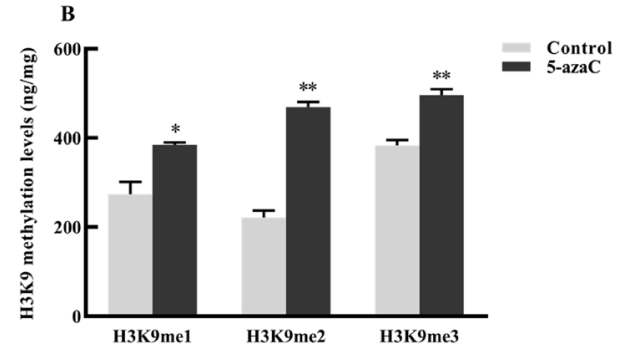

treated with 5-azaC; *compared with the control group, $p<0.05$, **compared with the control group, $p<0.01$
Table 3 Chlorogenic acid, flavonoid, and iridoid content of L. japonica treated with 5-azaC

\begin{tabular}{llcr}
\hline Category & Analyte & Control $(\mu \mathrm{g} / \mathrm{g})$ & 5-azaC $(\mu \mathrm{g} / \mathrm{g})$ \\
\hline Chlorogenic acids & Chlorogenic acid & $1903.44 \pm 133.24$ & $576.82 \pm 51.91^{*}$ \\
& Neochlorogenic acid & $74.67 \pm 1.99$ & $25.51 \pm 2.52^{*}$ \\
& Cryptochlorogenic acid & $14.43 \pm 0.58$ & $6.01 \pm 0.20^{*}$ \\
& Isochlorogenic acid A & $123.80 \pm 8.58$ & $31.48 \pm 2.20^{*}$ \\
& Isochlorogenic acid C & $13.53 \pm 0.77$ & $5.25 \pm 0.37^{*}$ \\
Flavonoids & Luteolin & $75.95 \pm 5.32$ & $427.01 \pm 24.89^{* *}$ \\
& Luteoloside & $994.33 \pm 33.81$ & $1368.20 \pm 46.52^{*}$ \\
Iridoids & Loganic acid & $66.58 \pm 4.29$ & $32.46 \pm 2.27^{*}$ \\
& Loganin & $168.30 \pm 16.32$ & $72.26 \pm 5.06^{*}$ \\
& 7-epi-loganin & $2536.57 \pm 177.56$ & $1037.17 \pm 48.23^{*}$ \\
& Secoxyloganin & $571.71 \pm 40.02$ & $196.32 \pm 13.74^{*}$ \\
\hline
\end{tabular}

*Compared with the control group, $p<0.05$, **Compared with the control group, $p<0.01$ 


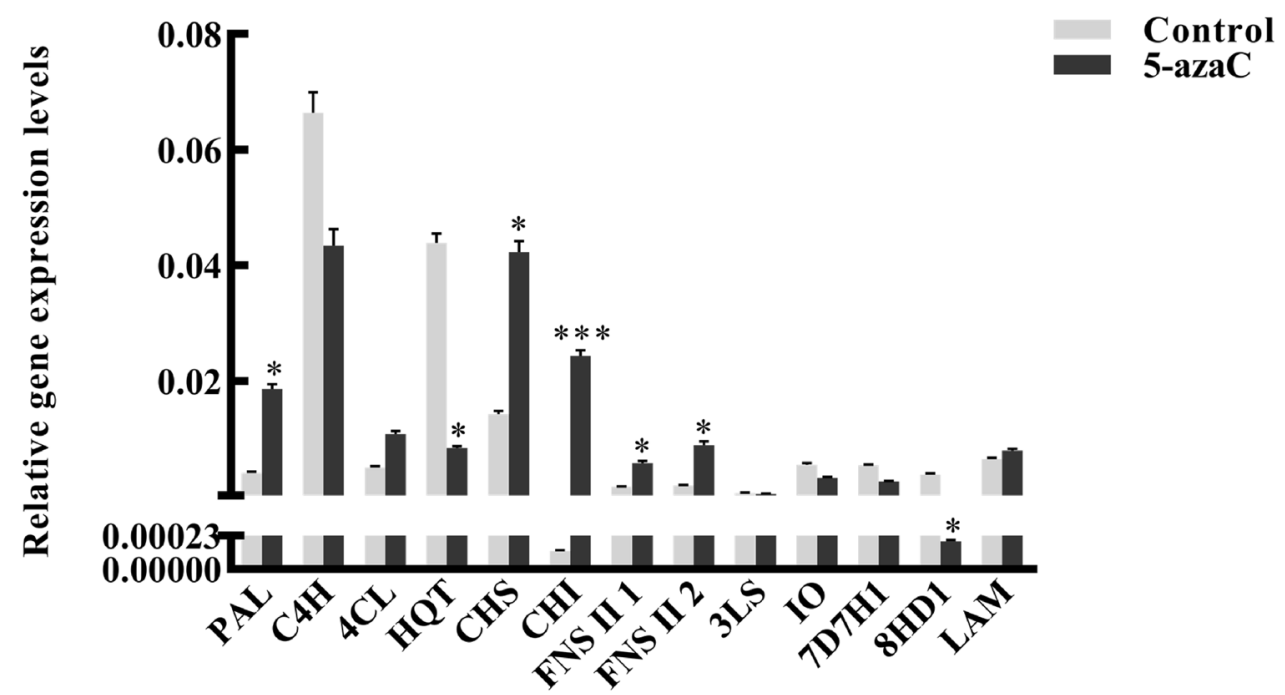

Fig. 4 Expression levels of genes involved in active compound biosynthesis in L. japonica. Control group, untreated leaves; 5-azaC group, leaves treated with 5-azaC. PAL phenylalanine ammonia-lyase, $C 4 H$ cinnamate 4-hydroxylase, $4 C L$ 4-coumarate CoA ligase, $H Q T$ hydroxycinnamoyl-CoA quinate transferase, $C H S$ chalcone synthase,

\section{Histone methylation levels and bioactive compounds in $L$. japonica from different producing areas}

To further validate the relationship between $\mathrm{H} 3 \mathrm{~K} 4 / \mathrm{H} 3 \mathrm{~K} 9$ methylation level and the content of bioactive compounds in L. japonica, we analyzed $\mathrm{H} 3 \mathrm{~K} 4$ and $\mathrm{H} 3 \mathrm{~K} 9$ methylation levels in $L$. japonica from different producing areas after plant introduction. The results indicated higher levels of $\mathrm{H} 3 \mathrm{~K} 4 \mathrm{me} 2$ and $\mathrm{H} 3 \mathrm{~K} 4 \mathrm{me} 3$ in buds obtained from Beijing than in buds obtained from Yunnan (Fig. 5a). Meanwhile, a significant difference $(p<0.05)$ in $\mathrm{H} 3 \mathrm{~K} 9 \mathrm{me} 3$ level was also observed between buds from Yunnan and Beijing as well as between buds from Yunnan and Hebei (Fig. 5b).

The relative content of chlorogenic acids was almost the same in the four producing areas. Luteolin level was significantly lower in buds from Hebei as compared to buds from Yunnan $(p<0.05)$. The content of loganic acid was also significantly different between buds from Yunnan and Hebei $(p<0.05)$ (Fig. 5c).
CHI chalcone isomerase, FNSII flavone synthase II, $3 L S$ (3S)-linalool/(E)-nerolidol synthase, $I O$ iridoid oxidase, $7 D 7 H$ 7-deoxyloganic acid 7-hydroxylase, $8 H D$ 8-hydroxygeraniol dehydrogenase, LAM (E)-beta-ocimene/myrcene synthase. ${ }^{*} p<0.05 ; * * * p<0.001$

\section{Discussion}

\section{Analysis of histone methylase in L. japonica}

Epigenetic regulatory mechanisms involve DNA methylation, noncoding RNAs, and histone modification [37]. Results of protein domain analysis and BLAST suggest that HMT1 belongs to the SVUH9 subgroup of SU(VAR)3-9 family and HMT4 belongs to the SUVH1 subgroup of SU(VAR)3-9 family. SVUH9 from Arabidopsis thaliana silence transcribed genes through heterochromatin condensation [38], which is related to the methylation of H3K9. Therefore, we speculated that HMT1 is related to the methylation of histone H3K9. The SRA domain of the histone methyltransferase SUVH family directly binds to methylated DNA, and simultaneously demethylates histone H3K9 [39]. Studies have shown that SUVH1 is related to H3K9 methylation, but unlike SUVH9, it acts downstream of DNA methylation in the
Fig. 5 Histone methylation levels and active compound content in L. japonica from different producing areas (Yunnan, Beijing, Hubei, and Hebei). a Methylation levels of $\mathrm{H} 3 \mathrm{~K} 4$; b methylation levels of $\mathrm{H} 3 \mathrm{~K} 9$; and c content of active compounds. $* p<0.05, * * p<0.01,{ }^{\# \#} p<0.01$, ${ }^{\#} p<0.05$

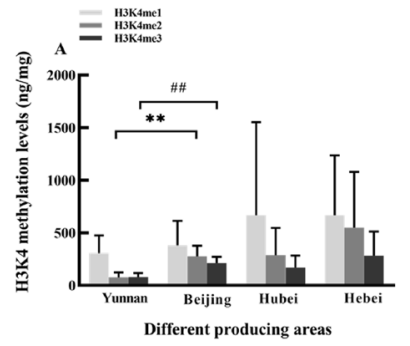

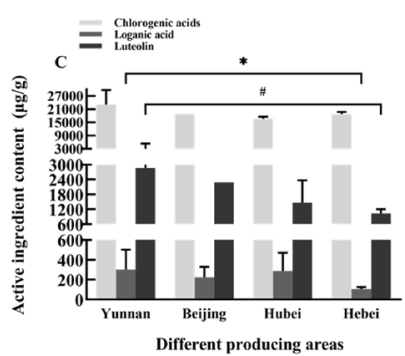


promoter region with anti-gene silencing effect, which is related to H3K4me3 [40]. Thus, we considered that HMT4 is both related to the methylation of histone $\mathrm{H} 3 \mathrm{~K} 9 \mathrm{me}$ and H3K4me3.

Histone lysine demethylase can be classified into two major categories: lysine-specific demethylase 1 (LSD1) and Jmjc domain-containing histone demethylases (JHDM) [41]. HDT2 belonged to the JHDM group, and their sequences were similar to that of JMJ25/JMJ25-like H3K9 demethylase [42]. Lysine demethylases containing the JmjC domain could demethylate multiple sites including $\mathrm{H} 3 \mathrm{~K} 4$ and $\mathrm{H} 3 \mathrm{~K} 9$ [43]. Therefore, we concluded that HDT2 is related to the methylation of histone H3K9.

\section{Effects of H3K4 and H3K9 methylation levels on active compound content and the expression levels of biosynthetic genes}

Bioinformatic analysis of histone methyltransferase and demethylase genes from $L$. japonica transcriptome data showed that these genes are mainly associated with $\mathrm{H} 3 \mathrm{~K} 4$ and $\mathrm{H} 3 \mathrm{~K} 9$ methylation. Among them, H3K4me 3 and $\mathrm{H} 3 \mathrm{~K} 9 \mathrm{me} 1 / 2 / 3$ play a key role in histone methylation in $L$. japonica. The $\mathrm{H} 3 \mathrm{~K} 4 \mathrm{me} 3$ region is mainly distributed in the euchromatin region, which is related to gene expression and promotes gene transcription [44]. Meanwhile, $\mathrm{H} 3 \mathrm{~K} 9 \mathrm{me}$ is regarded as a hallmark of heterochromatin and gene silencing.

5-AzaC is a nucleotide analog that decreases DNA methyltransferase activity [45]. Recent studies have shown that 5-azaC influences histone H3K9me3 and H3K27me3 methylation levels [46]. Therefore, we attempted to illustrate the relationship among histone methylation, active compounds, and relative gene expression with the help of 5-azaC.

Histone methylation modification regulate the expression of key enzyme genes in the biosynthetic pathway of secondary metabolites in a variety of ways, which affects the accumulation of secondary metabolites to improve stress resistance in plants $[47,48]$. The loss of ATX1 cause the levels of $\mathrm{H} 3 \mathrm{~K} 4 \mathrm{me} 3$, NCED3 and ABA reduced in atx 1 mutant $[49,50]$. SDG8 and SDG25 contribute to plant immunity through histone methylation and regulating expression of plant immunity genes, accumulation of lipids, biosynthesis of carotenoids, and maintenance of cuticle integrity [51]. Combined with the results, we speculated that the significant changes in the content of active compounds and expression levels of related genes were due to variations in $\mathrm{H} 3 \mathrm{~K} 9$ and H3K4me3 levels. H3K9 methylation level negatively correlated with luteolin content, while H3K4me3 level positively correlated with chlorogenic acid and loganic acid content (Fig. 6). Therefore, histone methylation might influence secondary metabolite biosynthesis in L. japonica by transcriptionally regulating the expression of biosynthetic genes.

\section{Histone methylation levels and bioactive compounds in $L$. japonica from different producing areas}

Chromatin remodeling affects a range of life processes, including flowering time, stress memory, and secondary metabolism [52]. It has been reported that regulation of histone methylation in plant defense and flowering is related to secondary metabolism [53]. However, it is unclear whether a similar link exists between active compound biosynthesis and histone methylation in medicinal plants from different
Fig. 6 Schematic diagram of regulation of active compound biosynthesis by histone methylation. The red arrows indicate increased methylation levels, gene expression levels and content; and the green arrows indicate the opposite
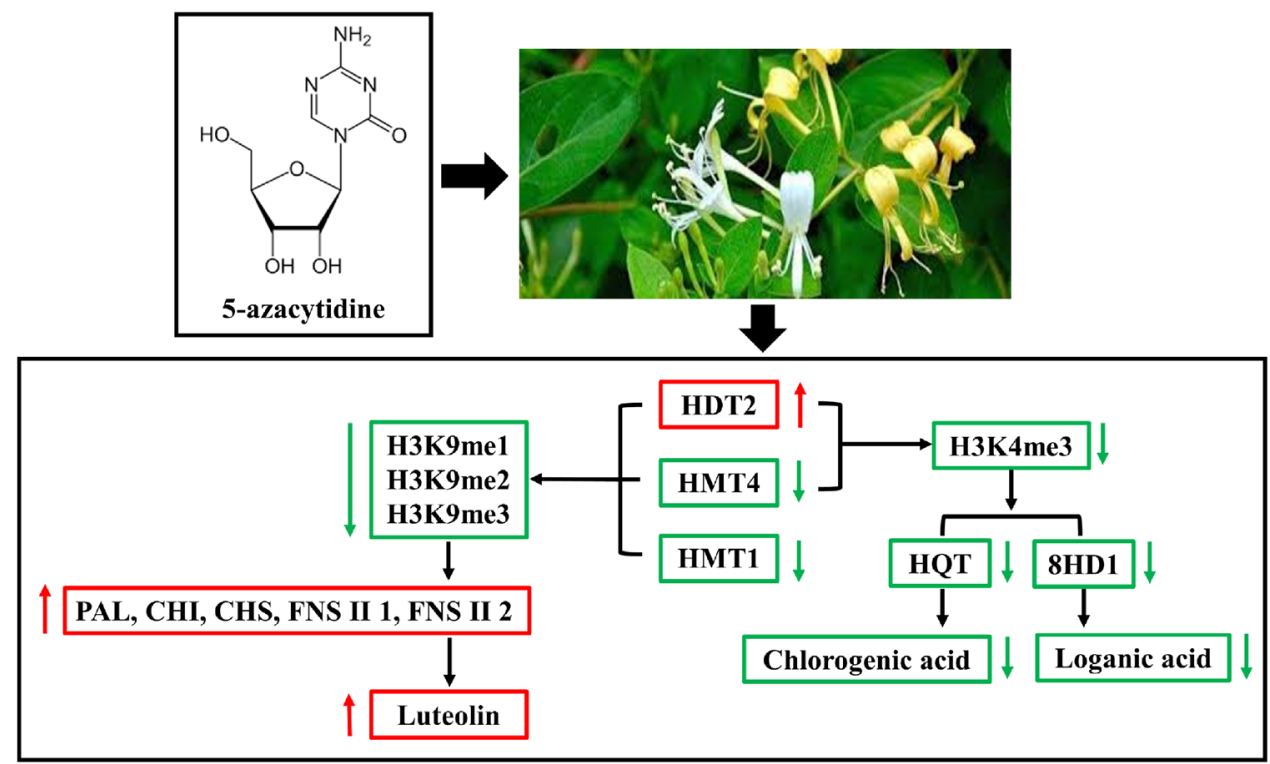
regions. Fengqiu in Henan, Pingyi in Shandong, and Julu in Hebei are the three main L. japonica producing areas [54]. The phenotype of $L$. japonica and the methylation level of genes for key enzymes are closely related to the place of origin and are easily affected by biological and abiotic factors in the environment. DNA methylation and miRNAs play vital regulatory roles in phenotype of $L$. japonica $[34,55]$.

In order to exclude the impact of germplasm on histone methylation, similar varieties were selected from Beijing and introduced to three other geographical locations. The results showed that $\mathrm{H} 3 \mathrm{~K} 4 \mathrm{me} 2 / 3$ methylation levels in L. japonica from Yunnan were significantly different from that in Beijing, while H3K9me3 methylation levels were significantly different between L. japonica from Yunnan and Hebei. Metabolomic analysis has revealed obvious differences in the chemical composition of L. japonica from different producing areas [56]. In this study, we found that luteolin content was different between $L$. japonica from Yunnan and Hebei. The main components of $L$. japonica including chlorogenic acid and loganic acid were not significantly different among $L$. japonica from the four producing areas. A comprehensive analysis of L. Japonica from four producing areas showed that the expression of genes involved in active compound biosynthetic pathway was also related to histone $\mathrm{H} 3 \mathrm{~K} 4$ and $\mathrm{H} 3 \mathrm{~K} 9$ methylation levels. Therefore, H3K4 methylation may regulate the chlorogenic acid and iridoid biosynthetic pathway in L. japonica. Thus, variation of histone methylation level in L. japonica indicates that the regulation of epigenetic modifications of active compounds is closely related to the environment.

\section{Conclusion}

In conclusion, our study is the first to demonstrate a potential regulatory network of $\mathrm{H} 3 \mathrm{~K} 9 / \mathrm{H} 3 \mathrm{~K} 4$ methylation, transcription of secondary biosynthetic genes, content of secondary metabolites in L. japonica, and is also the first report revealing the regulatory mechanism of histone methylation in medicinal plants. Our findings on the role of histone $\mathrm{H} 3 \mathrm{~K} 4$ and $\mathrm{H} 3 \mathrm{~K} 9$ methylation in secondary metabolism of $L$. japonica open an interesting perspective for understanding the possible molecular mechanism of regulation of bioactive compound synthesis in functional plants. Moreover, our results demonstrate that the levels of histone $\mathrm{H} 3 \mathrm{~K} 4 \mathrm{me} 3$ and H3K9me3 can be used as molecular markers for evaluating the quality of chlorogenic acids, flavonoids, and iridoids in L. japonica.

Acknowledgements This research was financially supported by National Natural Science Foundation of China (NSFC) (81891013/81891010), the Fundamental Research Funds for the Central Public Welfare Research Institutes (ZZ10-008) and Key Project at
Central Government Level for the Ability Establishment of Sustainable Use for Valuable Chinese Medicine Resources (2060302).

Author contributions YY designed experiments; JY and SL performed the experiments; TL analyzed the data and wrote the original draft paper; YZ, JZ and YJ supervised the study; LH revised the manuscript. All authors have read and agreed to the published version of the manuscript.

\section{Compliance with ethical standards}

Conflict of interest The authors declare that they have no known competing financial interests or personal relationships that could have appeared to influence the work reported in this paper.

Research involving human participants and/or animals No human participants participated in this study.

\section{References}

1. Li JJ, Lian XY, Ye CL, Wang L (2019) Analysis of flower color variations at different developmental stages in two honeysuckle (Lonicera japonica Thunb.) cultivars. HortScience 54(5):779782. https://doi.org/10.21273/Hortsci3819-18

2. Lin L, Wang P, Du Z, Wang W, Cong Q, Zheng C, Jin C, Ding K, Shao C (2016) Structural elucidation of a pectin from flowers of Lonicera japonica and its antipancreatic cancer activity. Int J Biol Macromol 88:130-137. https://doi.org/10.1016/j.ijbio mac.2016.03.025

3. Ding Y, Cao Z, Cao L, Ding G, Wang Z, Xiao W (2017) Antiviral activity of chlorogenic acid against influenza A (H1N1/H3N2) virus and its inhibition of neuraminidase. Sci Rep 7:45723. https ://doi.org/10.1038/srep45723

4. Wang L, Jiang Q, Hu J, Zhang Y, Li J (2016) Research progress on chemical constituents of Lonicerae japonicae flos. Biomed Res Int 2016:8968940. https://doi.org/10.1155/2016/8968940

5. Tian W, Fan SS, Zhen YQ, Feng Y, Chen Z, Niu LY (2019) Comparison of eleven active components in Lonicerae japonicae flos, Lonicerae japonicae caulis and leaves of Lonicero japonica by UPLC. China J Chin Mater Med 44(1):100-105

6. Qi X, Fang H, Chen Z, Liu Z, Yu X, Lian C (2019) Ectopic expression of a R2R3-MYB transcription factor gene LjaMYB12 from Lonicera japonica increases flavonoid accumulation in Arabidopsis thaliana. J Mol Sci 20(18):4494. https://doi.org/10.3390/ijms2 0184494

7. Liu ZX, Liu CT, Liu QB, Ren J, Li LZ, Huang XX, Song SJ (2015) Iridoid glycosides from the flower buds of Lonicera japonica and their nitric oxide production and $\alpha$-glucosidase inhibitory activities. J Funct Foods 18(Part A):512-519

8. Oboh G, Agunloye OM, Akinyemi AJ, Ademiluyi AO, Adefegha SA (2012) Comparative study on the inhibitory effect of caffeic and chlorogenic acids on key enzymes linked to Alzheimer's disease and some pro-oxidant induced oxidative stress in rats' brain in vitro. Neurochem Res 38:413-419. https://doi.org/10.1007/ s11064-012-0935-6

9. Li YF, Shen D, Tang XM, Li X, Wo D, Yan HW, Song R, Feng J, Li P, Zhang J, Li J (2014) Chlorogenic acid prevents isoproterenol-induced hypertrophy in neonatal rat myocytes. Toxicol Lett 226(3):257-263. https://doi.org/10.1016/j.toxlet.2014.02.016

10. Mahboob T, Azlan AM, Tan TC, Samudi C, Sekaran SD, Nissapatorn V, Wiart C (2016) Anti-encystment and amoebicidal activity 
of Lonicera japonica Thunb. and its major constituent chlorogenic acid in vitro. Asian Pac J Trop Med 9(9):866-871

11. Yang J, Li YC, Zhou XR, Xu XJ, Fu QY, Liu CZ (2017) Two thymol derivatives from the flower buds of Lonicera japonica and their antibacterial activity. Nat Prod Res 32(18):2238-2243. https ://doi.org/10.1080/14786419.2017.1371153

12. Liu M, Yu Q, Yi Y, Xiao H, Putra DF, Ke K, Zhang Q, Li P (2019) Antiviral activities of Lonicera japonica Thunb. Components against grouper iridovirus in vitro and in vivo. Aquaculture 519:734882. https://doi.org/10.1016/j.aquaculture.2019.734882

13. Bang BW, Park D, Kwon KS, Lee DH, Jang MJ, Park SK, Kim JY (2019) BST-104, a water extract of Lonicera japonica, has a gastroprotective effect via antioxidant and anti-inflammatory activities. J Med Food 22(2):140-151. https://doi.org/10.1089/ jmf.2018.4231

14. Shah M, Ullah M, Drouet S, Younas M, Tungmunnithum D, Giglioli-Guivarch N, Hano C, Abbasi BH (2019) Interactive effects of light and melatonin on biosynthesis of silymarin and antiinflammatory potential in callus cultures of Silybum marianum (L.) Gaertn. Molecules 24:1207

15. Yang R, Hao H, Li J, Xuan J, Xia MF, Zhang YQ (2020) Three new secoiridoid glycosides from the flower buds of Lonicera japonica. Chin J Nat Med 18(1):70-74. https://doi.org/10.1016/ s1875-5364(20)30006-6

16. He L, Xu X, Li Y, Li C, Zhu Y, Yan H, Sun Z et al (2013) Transcriptome analysis of buds and leaves using 454 pyrosequencing to discover genes associated with the biosynthesis of active ingredients in Lonicera japonica Thunb. PLoS ONE 8(4):e62922. https ://doi.org/10.1371/journal.pone.0062922

17. Zhao YY, Yang QR, Hao JB, Li WD (2016) Research progress on pharmacological effects and their differences among the flowers, stems and leaves of Lonicera japonica. China J Chin Mater Med 41(13):2422-2427. https://doi.org/10.4268/cjcmm20161309

18. Machida K, Sasaki H, Iijima T, Kikuchi M (2002) Studies on the constituents of Lonicera species. XVII. New iridoid glycosides of the stems and leaves of Lonicera japonica Thunb. Chem Pharm Bull 50(8):1041-1044. https://doi.org/10.1248/cpb.50.1041

19. Kakuda R, Imai M, Yaoita Y, Machida K, Kikuchi M (2000) Secoiridoid glycosides from the flower buds of Lonicera japonica. Phytochemistry 55(8):879-881. https://doi.org/10.1016/s0031 -9422(00)00279-x

20. Suksamrarn A, Kumpun S, Kirtikara K, Yingyongnarongkul B, Suksamrarn S (2002) Iridoids with anti-inflammatory activity from vitex peduncularis. Planta Med 68:72-73. https://doi. org/10.1055/s-2002-20048

21. Viljoen A, Mncwangi N, Vermaak I (2012) Anti-inflammatory iridoids of botanical origin. Curr Med Chem 19:2104-2127. https ://doi.org/10.2174/092986712800229005

22. Han N, Zheng F (2013) Determination of loganin in Lonicera japonica Thunb. in different harvest period. J Pediatr Pharm 19(3):47-49

23. Tundis R, Loizzo M, Menichini F, Statti G, Menichini F (2008) Biological and pharmacological activities of iridoids: recent developments. Mini Rev Med Chem 8(4):399-420. https://doi. org/10.2174/138955708783955926

24. Chen XY, Qin SS, Li C, Wu QH, Jiang C, Yang J, Guo X, Ou CL (2019) Differential gene expressions and phytohormone changes altered Lonicera japonica quality after plant introduction. Pharmacognosy Mag 15(60):18-23. https://doi.org/10.4103/ pm.pm_317_18

25. Nabavi SM, Šamec D, Tomczyk M, Milella L, Russo D, Habtemariam S et al (2018) Flavonoid biosynthetic pathways in plants: Versatile targets for metabolic engineering. Biotechnol Adv 38:107316. https://doi.org/10.1016/j.biotechadv.2018.11.005

26. Shitiz K, Sharma N, Pal T, Sood H, Chauhan RS (2015) NGS transcriptomes and enzyme inhibitors unravel complexity of picrosides biosynthesis in Picrorhiza kurroa Royle ex. Benth PLoS ONE 10(12):e0144546. https://doi.org/10.1371/journ al.pone. 0144546

27. Qin S, Chen X, Jiang C, Li M, Yuan Y, Yang J, Wu Q (2019) Pruning induced yield and quality variations and the correlated gene expression and phytohormone changes in Lonicera japonica. Ind Crops Prod 132:386-395. https://doi.org/10.1016/j. indcrop.2019.02.048

28. Yuan Y, Song L, Li M, Liu G, Chu Y, Ma L et al (2012) Genetic variation and metabolic pathway intricacy govern the active compound content and quality of the Chinese medicinal plant Lonicera japonica Thunb. BMC Genomics 13:195. https://doi. org/10.1186/1471-2164-13-195

29. Kong D, Li Y, Bai M, He H, Liang G, Wu H (2017) Correlation between the dynamic accumulation of the main effective components and their associated regulatory enzyme activities at different growth stages in Lonicera japonica Thunb. Ind Crops Prod 96:16-22. https://doi.org/10.1016/j.indcrop.2016.11.024

30. Yuan Y, Wang Z, Jiang C, Wang X, Huang LQ (2014) Exploiting genes and functional diversity of chlorogenic acid and luteolin biosyntheses in Lonicera japonica and their substitutes. Gene 534(2):408-416. https://doi.org/10.1016/j.gene.2012.09.051

31. Kong L, Liu Y, Wang X, Chang C (2020) Insight into the role of epigenetic processes in abiotic and biotic stress response in wheat and barley. Int J Mol Sci 21(4):1480. https://doi. org/10.3390/ijms21041480

32. Liu J, Yuan Y, Wang Y, Jiang C, Chen T, Zhu FJ, Zhao YY, Zhou JH, Huang LQ (2017) Regulation of fatty acid and flavonoid biosynthesis by miRNAs in Lonicera japonica. RSC Adv 7:35426-35437. https://doi.org/10.1039/c7ra05800d

33. Liu G, Khan N, Ma X, Hou X (2019) Identification, evolution, and expression profiling of histone lysine methylation moderators in Brassica rapa. Plants 8:526. https://doi.org/10.3390/ plants8120526

34. Mathieu O, Probst AV, Paszkowski J (2005) Distinct regulation of histone $\mathrm{H} 3$ methylation at lysines 27 and 9 by $\mathrm{CpG}$ methylation in Arabidopsis. EMBO J 24:2783-2791. https://doi. org/10.1038/sj.emboj.7600743

35. Wang X, Gao J, Gao S, Song Y, Yang Z, Kuai B (2019) The H3K27me3 demethylase REF6 promotes leaf senescence through directly activating major senescence regulatory and functional genes in Arabidopsis. PLoS Genet 15(4):e1008068. https://doi.org/10.1371/journal.pgen.1008068

36. Wang LY, Chen H, Li JJ, Shu HD, Zhang XX, Wang YC, Tyler BM, Dong SM (2019) Effector gene silencing mediated by histone methylation underpins host adaptation in an oomycete plant pathogen. Nucleic Acids Res 48(4):1790-1799. https:// doi.org/10.1093/nar/gkz1160

37. Michaels KK, Mostafa SM, Capella JR, Moore CL (2020) Regulation of alternative polyadenylation in the yeast Saccharomyces cerevisiae by histone $\mathrm{H} 3 \mathrm{~K} 4$ and $\mathrm{H} 3 \mathrm{~K} 36$ methyltransferases. Nucleic Acids Res 48(10):5407-5425. https://doi.org/10.1093/ nar/gkaa292

38. Jing YQ, Sun H, Yuan W, Wang Y, Li Q, Liu YN, Li Y, Qian WQ (2016) SUVH2 and SUVH9 couple two essential steps for transcriptional gene silencing in Arabidopsis. Mol Plant 9(8):1156-1167. https://doi.org/10.1016/j.molp.2016.05.006

39. Rajakumara E, Law JA, Simanshu DK, Voigt P, Johnson LM, Reinberg D, Patel DJ, Jacobsen SE (2011) A dual flip-out mechanism for $5 \mathrm{mC}$ recognition by the Arabidopsis SUVH5 SRA domain and its impact on DNA methylation and H3K9 dimethylation in vivo. Genes Dev 25(2):137-152. https://doi. org/10.1101/gad.1980311

40. Li S, Liu L, Li S, Gao L, Zhao Y, Kim YJ, Chen X (2015) SUVH1, a Su(var)3-9 family member, promotes the expression 
of genes targeted by DNA methylation. Nucleic Acids Res 44(2):608-620. https://doi.org/10.1093/nar/gkv958

41. Tsukada Y, Fang J, Erdjument-Bromage H, Warren ME, Borchers CH, Tempst P, Zhang Y (2005) Histone demethylation by a family of JmjC domain-containing proteins. Nature 439:811-816. https ://doi.org/10.1038/nature04433

42. Luo M, Hung FY, Yang SG, Liu XC, Wu KQ (2013) Histone lysine demethylases and their functions in plants. Plant Mol Biol Rep 32:558-565. https://doi.org/10.1007/s11105-013-0673-1

43. Nottke A, Colaiacovo MP, Shi Y (2009) Developmental roles of the histone lysine demethylases. Development 136:879-889. https ://doi.org/10.1242/dev.020966

44. Liu P, Zhang SB, Zhou B, Luo X, Zhou XF, Cai B, Jin HY, Niu D, Lin JX, Cao XF, Jin JB (2019) The histone H3K4 demethylase JMJ16 represses leaf senescence in Arabidopsis. Plant Cell 31:430-443. https://doi.org/10.1105/tpc.18.00693

45. Grzybkowska D, Morończyk J, Wójcikowska B, Gaj MD (2018) Azacitidine (5-AzaC)-treatment and mutations in DNA methylase genes affect embryogenic response and expression of the genes that are involved in somatic embryogenesis in Arabidopsis. Plant Growth Regul 85:243-256. https://doi.org/10.1007/s1072 5-018-0389-1

46. Lee E, Wang J, Jung Y, Cackowski FC, Taichman RS (2018) Reduction of two histone marks, H3k9me3 and H3k27me3 by epidrug induces neuroendocrine differentiation in prostate cancer. J Cell Biochem 119(4):3697-3705. https://doi.org/10.1002/ jcb. 26586

47. Lawrence M, Daujat S, Schneider R (2016) Lateral thinking: How histone modifications regulate gene expression. Trends Genet 32(1):42-56. https://doi.org/10.1016/j.tig.2015.10.007

48. Zhang M, Xie SJ, Dong XM, Zhao X, Zeng B, Chen J, Li H, Yang WL, Zhao HN, Wang GK, Chen ZL, Sun SL, Hauck A, Jin WW, Lai JS (2014) Genome-wide high resolution parentalspecific DNA and histone methylation maps uncover patterns of imprinting regulation in maize. Genome Res 24(1):167-176. https ://doi.org/10.1101/gr.155879.113

49. Ashapkin VV, Kutueva LI, Aleksandrushkina NI, Vanyushin BF (2020) Epigenetic mechanisms of plant adaptation to biotic and abiotic stresses. Int J Mol Sci 21(20):7457. https://doi. org/10.3390/ijms21207457

50. Ding Y, Avramova Z, Fromm M (2011) The Arabidopsis trithorax-like factor ATX1 functions in dehydration stress responses via ABA-dependent and ABA-independent pathways. Plant J 66(5):735-744. https://doi.org/10.1111/j.1365-313X.2011.04534 .X

51. Lee SH, Fu FY, Xu SM, Lee SY, Yun DJ, Mengiste T (2016) Global regulation of plant immunity by histone lysine methyl transferases. Plant Cell 28(7):1640-1661. https://doi.org/10.1105/ tpc. 16.00012

52. Lindermayr C, Rudolf EE, Durner J, Groth M (2020) Interaction between metabolism and chromatin in plant models. Mol Meta 38:100951. https://doi.org/10.1016/j.molmet.2020.01.015

53. Li Y, Mukherjee I, Thum KE, Tanurdzic M, Katari MS, Obertello M et al (2015) The histone methyltransferase SDG8 mediates the epigenetic modification of light and carbon responsive genes in plants. Genome Biol 16(1):79. https://doi.org/10.1186/s1305 9-015-0640-2

54. Zhang SS, Yuan Y, Huang LQ, Chen P (2015) Study on characteristics of non-glandular hairs of cultivated Lonicera japonica. China J Chin Mater Med 40(3):390-394

55. Zha LP, Liu S, Liu J, Jiang C, Yu SL, Yuan Y, Yang J, Wang YL, Huang LQ (2017) DNA methylation influences chlorogenic acid biosynthesis in Lonicera japonica by mediating LjbZIP8 to regulate phenylalanine ammonia-lyase 2 expression. Front Plant Sci 8:1178. https://doi.org/10.3389/fpls.2017.01178

56. Zhu FJ, Yang J, Yuan Y, Jin Y, Zhao YY, Huang LQ (2018) Chemical fingerprinting and similarity analysis of Lonicera japonica resources. China J Chin Mater Med 43(12):2575-2579

Publisher's Note Springer Nature remains neutral with regard to jurisdictional claims in published maps and institutional affiliations. 